\title{
Default in the outpatient treatment of tuberculosis in two hospitals in Northern India
}

\author{
Joanna B Reed, Rachel McCausland, J Mark Elwood
}

\begin{abstract}
Study objective-The purpose of the study was to examine default rates in tuberculosis treatment in two hospitals in north India with different follow up arrangements.

Design-The study was a retrospective cohort study.

Setting-Two hospitals were involved. One was the District Tuberculosis Centre for the Kulu Valley area of Himachal Pradesh. The other was a private mission hospital serving the same area.

Patients-The study involved 321 patients at the tuberculosis centre and 381 at the mission hospital, being all those newly diagnosed with tuberculosis from October 1982 to September 1983; follow-up to October 1984. Patients at the mission hospital were more affluent and had travelled much further to seek treatment; only one reminder was sent to defaulters from treatment. The government hospital had a more active response if the patients missed an appointment, with a home visit by a health worker.

Results-Rates of permanent default were similar in each hospital and were very high: approximately $40 \%$ at 6 months, $60 \%$ at 12 months, and $65 \%$ at 18 months of treatment. Conclusions-Default was a major problem irrespective of the follow up procedures employed. Recommendations are made concerning treatment and follow up, including better communication about the disease and its treatment, active follow up of defaulters, and review of treatment policies.
\end{abstract}

From the Department of Community Medicine and Epidemiology, University of Nottingham, Queen's Medical Centre, Nottingham, UK. Joanna B Reed Rachel McCausland J Mark Elwood*

Address for correspondence and reprints:

Professor R J Madeley,

Department of Community

Medicine and Epidemiology,

University of Nottingham

Medical School, Queen's

Medical Centre, Nottingham NG7 2UH, UK.

^Current address:

Department of Preventive and Social Medicine, University of Otago, Box 913, Dunedin, New

Zealand.

Accepted for publication May 1989 Outpatient treatment of tuberculosis compares well to inpatient treatment in terms of clinical outcome $e^{1-3}$ and risk of infection of family contacts, ${ }^{4}$ but compliance over the long (12-24 problem. In Bangalore, only $20 \%$ of patients were still attending 12 months after the initiation of treatment. ${ }^{5}$ Failure of compliance has been shown to be associated with a reduced sputum conversion rate, ${ }^{6}$ and an increased clinical relapse rate. ${ }^{7}$

Factors associated with default from treatment in India vary in different studies. Higher default rates have been found in patients of higher caste ${ }^{8}$ or higher income, ${ }^{5}$ although not consistently, 9 and in those living further from the treatment centre. ${ }^{1011}$ Higher default rates have been found in females in some studies, ${ }^{1012}$ but in males in another ${ }^{11}$ Higher default rates have been found in sputum negative patients, ${ }^{51314}$ perhaps because they are less ill. In a randomised comparison, higher default was found in patients on biweekly supervised treatment involving travel to the treatment centre, compared to daily self administered treatment, requiring travel only once per month. ${ }^{11}$ Another comparison of treatment regimes showed no differences, but was based on inadequate numbers. ${ }^{15}$

The usual procedure for managing default in the Indian national tuberculosis programme is for patients who miss an appointment to be sent a letter within three days, and then visited by a health worker a week later if necessary. In a comparison of patients randomised either to this management or to a more intensive regimen with a health worker visiting four days after the first missed appointment, and if necessary three times more in the next two months, the more intensive intervention gave a lower default rate, primarily due to the effects of the first two visits. ${ }^{16}$ The purpose of the present study was to examine default rates in all patients starting tuberculosis treatment in a one year period in two hospitals in Northern India.

\section{Methods}

THE HOSPITALS

The study arose from the opportunity to compare two hospitals providing different types of tuberculosis treatment, and between them providing the only medical services for the Kulu Valley area of Himachal Pradesh. In this area, $97 \%$ of the population are Hindu, $71 \%$ are involved in agriculture, $34 \%$ are literate; the district population is 239000 (1981 census). The two hospitals concerned are the District Tuberculosis Centre in Kulu, and a private mission hospital, the Lady Willingdon Hospital (LWH) in Manali, 40 kilometres to the north

The District Tuberculosis Centre is supported months) time period necessary is a major 
second letter. Patients who then return to treatment are counselled to encourage greater motivation.

The private mission hospital makes charges for all drugs and treatment and inpatient care, with exceptions for the poorest patients, and has no well established community health worker network, although some is developing. ${ }^{17}$ Patients are self referred, and first line treatment uses daily streptomycin, isoniazid and thiacetazone for three months, followed by isoniazid (plus pyridoxine) and thiacetazone daily for 21 months. Streptomycin vials can be taken by the patient to a local dispensary or private doctor for the daily injections. Defaulter action is less intensive, patients who miss appointments being sent postcards after a week, with no further action being taken.

\section{PROCEDURE}

All patients starting treatment for newly diagnosed tuberculosis between 1st October 1982 and 30th September 1983 at either hospital were identified, and the last known status of all patients up to October 1984 recorded. The only exclusions were patients who had moved and notified the treatment centre of their move, and for whom other care had been arranged. The eligible patients numbered 321 at Kulu District Tuberculosis Centre (for two others records could not be traced), and 381 at the private hospital. Temporary default was defined as being over three weeks late for an appointment, followed by rejoining the programme. Permanent default was absence for over one month without rejoining. Analysis was done by number of weeks of treatment given, being the time from date of start of treatment to the date of next appointment, deducting any lost time due to late attendance.

The data were collected by JR and RMcC, then 3rd year medical students at the University of Nottingham. Default rates by time from first treatment were calculated by the product-limit method, and differences between default rate curves for different groups of subjects assessed by the Mantel or log-rank test. ${ }^{18} 19$

\section{Results}

DIFFERENCES IN THE PATIENT GROUPS BETWEEN THE TWO HOSPITALS.

The groups of newly diagnosed tuberculosis patients at the two hospitals were similar in terms of age (mean 29 years), sex ( $53 \%$ female), religion (94\% Hindu), and occupation (70\% farmers,

Figure Cumulative proportion of patients defaulting from treatment by hospital and time of registration

$A=$ District $T B$ Centre

$(n=315) ; B_{1}=$ Voluntary hospital, all patients $(n=363) ; B_{2}=$ Voluntary hospital, patients registered at first visit $(n=161)$

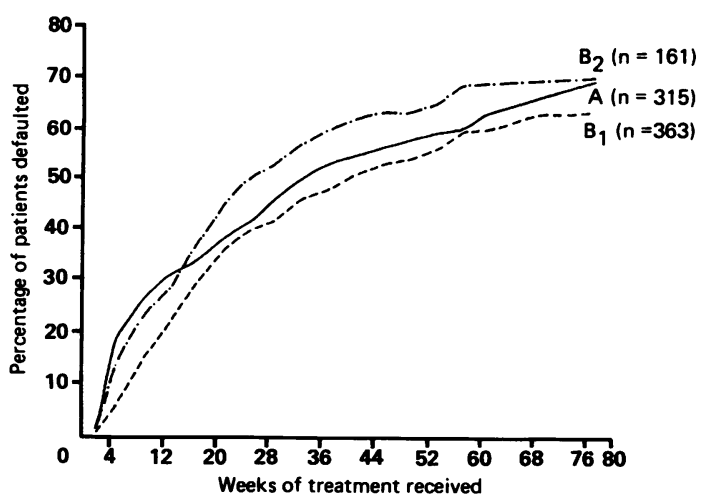

$15 \%$ government employees). They differed in that patients at the voluntary hospital tended to be of higher caste $(11 \%$ high and $19 \%$ low caste, compared to $7 \%$ and $33 \%$ respectively at the District Tuberculosis Centre), and in the distance they lived from the hospital. Eighty per cent of patients at the voluntary hospital lived more than 10 kilometres away, compared to $26 \%$ of those from the District Tuberculosis Centre. Eighty four per cent of the patients in the District Tuberculosis Centre had pulmonary tuberculosis only compared to $64 \%$ at the voluntary hospital. In each hospital, around $25 \%$ of patients had a period of inpatient care, but the mean length of stay at the District Tuberculosis Centre was 4.6 weeks compared to 1.4 weeks at the voluntary hospital.

\section{DEFAULT RATES}

The proportion of patients who had defaulted from treatment, that is who were at least one month late for an appointment and had not reappeared for treatment, was similar in the two hospitals (figure), and was very high; around 40\% after six months' treatment, $60 \%$ after one year's treatment, and $65 \%$ by the targeted 18 months' treatment. The comparison of default rates is complicated by difficulties in the record system at the voluntary hospital, where a high proportion of patients were not entered in the patient registry at the time of their first visit. If patients who are first entered in the registry only after some weeks of treatment are included, the default rate will be underestimated (because patients who default during those few weeks are not recorded). A correction for this is to examine only those patients who are entered into the record at the time of their first visit, and this results in higher default rates. However, whichever comparison is used the difference between the two hospitals was not significant: based on all patients the log rank test yields $\chi^{2}=3.71(p=0.054)$, and with the adjusted comparison, $\chi^{2}=0.4(p=0.5)$. Patients registered at their first visit may be somewhat atypical, and the true default rate for the voluntary hospital probably lies between the two curves shown, making it even closer to that of the other hospital.

\section{FACTORS ASSOCIATED WITH DEFAULT}

The analysis of factors associated with default is made more powerful by comparing default rates at 40 weeks (the average being $52 \%$ for the whole study group), and other analyses showed that the factors' effects did not vary greatly by follow up time. In the combined data, high default rates were seen in patients aged over 50 , in males, and in low caste patients, but there was little consistency between the two hospitals (table). Default rates increased strongly with age in the District Tuberculosis Centre, and only slightly in the voluntary hospital; the higher rate in males was seen primarily in the voluntary hospital. The highest default rate was in the low caste patients in the District Tuberculosis Centre, and in the medium caste patients in the voluntary hospital. In neither hospital did the default rate vary with the type of tuberculosis, the drug regimen used, or whether there had been a period of inpatient 
treatment. However in both hospitals, patients who had had a period of default which had then been corrected (temporary defaulters) had a much lower frequency of final default.

\section{Discussion}

This study showed that these two hospitals, which differ considerably in the patients they serve and in the methods they use to manage tuberculosis, have a major problem of default from outpatient treatment, with only some $50 \%$ of patients receiving at least six months treatment, and probably only $30 \%$ receiving the full recommended 18 months treatment. The similarity of the results between the hospitals may be because of a balancing of the different characteristics. The voluntary hospital caters for patients who have actively chosen it despite the cost, and who have for the most part travelled a considerable distance; the patients treated are more affluent. Although the voluntary hospital uses three drug rather than two drug initial therapy, and second line and more expensive drugs more frequently, it has shorter periods of inpatient treatment and has a much less intensive system of dealing with default. In Kulu District Tuberculosis Centre, the patients seen are less affluent and do not make a financial commitment, but action on first default is stronger and the hospital has the support of a network of community health workers. At the District Tuberculosis Centre $39 \%$ of all patients had one or more episodes of temporary default, compared to $25 \%$ at the voluntary hospital, despite the similarity in the final default rates. The voluntary hospital system, which is somewhat more flexible in that patients may be given a supply of drugs for two or three months, results in a lower frequency of first defaults, but the District Tuberculosis Centre system is more successful at dealing with patients who default once due to its more intensive follow up procedures.

Comparisons of default from different studies are complicated in variations of definition. Using a comparable definition to that used here, a default rate of $70 \%$ after 15 months' treatment was found in Bangalore. ${ }^{14}$ In southern Gujarat, a substantial recovery rate from an initial $71 \%$ default rate was found, yielding a final default rate of around $55 \%$ some five years from first diagnosis. $^{8}$
The analysis of routine data to assess factors related to default has not been particularly helpful, either in this study or in other published work, as it does not identify a specific high risk group to whom efforts could be directed. One encouraging fact is the lower final default rates of those who have recovered from a temporary default, which emphasises the value of efforts to identify and deal with temporary defaulters. There may be potential for improving the awareness of patients; in interview studies of patients at each of these hospitals done in conjunction with this study we found that about $25 \%$ of patients were given no information concerning the importance of long term treatment, and at the voluntary hospital patients were less well informed about the way in which they should take the drugs, perhaps because the typical clinic there had some 50 patients compared to 15 or 20 at a similar clinic at the District Tuberculosis Centre.

These results have been discussed with staff at both the hospitals concerned, and on the basis of these results and those of previous studies, the following recommendations are made regarding the treatment of outpatients with tuberculosis:

(1) Clear information on the disease, the drug therapy, and the importance of long term drug therapy should be given to patients, both in oral and written form.

(2) High priority should be given to an active policy for the follow up of temporary defaulters.

(3) Treatment policies should be assessed to see if treatment could be shortened, simplified or used more selectively. Consideration of the use of intermittent chemotherapy for patients living fairly near to centres should be considered.

(4) Initial registration of tuberculosis patients should be linked to the first prescription of drugs, perhaps by a pharmacist rather than the physician responsible for the initial registration of patients. ${ }^{20}$

This work formed part of the BMedSci dissertations of JBR and RMCC
Table Factors associated with default in each centre default rates at 40 weeks $(\%)$ by factor by hospital

\begin{tabular}{|c|c|c|c|c|c|c|}
\hline & \multicolumn{3}{|c|}{ District TB Centre } & \multicolumn{3}{|c|}{ Voluntary Hospital } \\
\hline & $\%$ Default & Number & $p$ & $\%$ Default & Number & $p$ \\
\hline $\begin{array}{l}\text { All patients } \\
\text { Age }<20 \\
\quad 20-49 \\
50+ \\
\text { Sex male } \\
\text { female } \\
\text { Caste high } \\
\text { medium } \\
\text { low } \\
\text { Type of TB pulmonary } \\
\text { extra-pulmonary } \\
\text { Treatment } 3 \text { drug } \\
2 \text { drug } \\
\text { Other } \\
\text { Temporary default No } \\
\quad \text { Yes }\end{array}$ & $\begin{array}{l}53 \cdot 6 \\
58 \cdot 2 \\
47 \cdot 2 \\
78 \cdot 3 \\
55 \cdot 8 \\
51 \cdot 6 \\
47 \cdot 4 \\
45 \cdot 3 \\
66 \cdot 7 \\
53 \cdot 8 \\
53 \cdot 1 \\
54 \cdot 2 \\
55 \cdot 2 \\
35 \cdot 7 \\
75 \cdot 0 \\
20 \cdot 3\end{array}$ & $\begin{array}{r}315 \\
67 \\
199 \\
47 \\
154 \\
161 \\
19 \\
179 \\
105 \\
260 \\
49 \\
120 \\
183 \\
14 \\
192 \\
123\end{array}$ & $\begin{array}{l}\text { NS } \\
0.002 \\
\text { NS } \\
\text { NS }\end{array}$ & $\begin{array}{l}49 \cdot 6 \\
47 \cdot 4 \\
48 \cdot 2 \\
54 \cdot 2 \\
55 \cdot 3 \\
45 \cdot 1 \\
53 \cdot 6 \\
36 \cdot 2 \\
56 \cdot 8 \\
50 \cdot 5 \\
47 \cdot 3 \\
49 \cdot 3 \\
33 \cdot 3 \\
47 \cdot 6 \\
56 \cdot 6 \\
28 \cdot 6\end{array}$ & $\begin{array}{r}363 \\
95 \\
224 \\
35 \\
159 \\
204 \\
28 \\
174 \\
44 \\
218 \\
131 \\
298 \\
6 \\
63 \\
272 \\
91\end{array}$ & $\begin{array}{l}0.02 \\
\text { NS } \\
\text { NS }\end{array}$ \\
\hline
\end{tabular}




\section{References}

1 Tuberculosis Chemotherapy Centre, Madras. A concurrent comparison of home and sanatorium treatment of pulmonary tuberculosis in South India. Bull WHO 1959; pulmonary

2 Velu S, Andrews RH, Devdatta S, et al. Progress in the second year of patients with quiescent pulmonary tuberculosis after a year of chemotherapy at home or in sanatorium, and influence of further chemotherapy on the relapse rate. Bull WHO 1960; 23: 511-33.

3 Fox W. Self-administration of medicaments. A review of published works and a study of the problems. Bull Int Union Tuberc Lung Dis 1962; 32: 307-30.

4 Andrews RH, Devadatta S, Fox W, Radhakrishna S, Ramakrishnan CV, Velu S. Prevalence of tuberculosis among close family contacts of tuberculous patients in South India, and influence of segregation of the patient on the early attack rate. Bull WHO 1960; 23: 462-510.

5 Anderson S, Banerii D. A sociological inquiry into an urban tuberculosis control programme in India. Bull Who 1963; 29: 685-700.

6 Pamra SP, Mathur GP. Drug default in an urban community. Indian $f$ Tuberc 1967; 14: 199-203.

7 Toman K. Tuberculosis case-finding and chemotherapy. Questions and answers. Geneva: WHO, 1979.

8 Mankodi K. Socio-cultural context of TB treatment: a case study of southern Gujarat. Indian $\mathcal{F}$ Tuberc 1982; 29: 87-92.

9 Seetha MA, Srikantaramu N, Aneja KS, Singh Hardan. Influence of motivation of patients and their family members on the drug collection by patients. Indian $f$ Tuberc 1981; 28: 182-90.

10 Cassels A, Heineman E, LeClerq S, Gurung PK, Rahut CB. Tuberculosis case-finding in Eastern Nepal. Tubercle 1982, 63: $175-85$.
11 Baily GVJ, Samuel GER, Nagpaul DR. A concurrent comparison of an unsupervised self-administered daily regimen and a fully supervised twice-weekly regimen of regimen and a fully supervised twice-weekly regimen of chemotherapy in a routine out-patient

12 Gothi GD, Savic D, Baily GVJ, Rao KP, Nair SS, Samuel R Cothi GD, Savic D, Baily GVJ, Rao KP, Nair SS, Samuel R. antection and consumption of self administered antituberculosis drugs under

13 Aneja KS, Seetha MA, Singh H, Leela V. Influence of initial motivation on treatment of tuberculosis patients. Indian $\mathcal{f}$ Tuberc 1980; 27: 123-9.

14 Seetha MA, Samuel GER, Naidu VB. A study of some operational aspects of treatment cards in a district tuberculosis programme. Indian $\mathcal{F}$ Tuberc 1976; 23: 90-7.

15 Srivastava VK, Chandra R, Jain PC, Bhatnagar JK. A study of drug default inpatients attending tuberculosis clinics in rural area. Indian of Tuberc 1981; 28: 26.

16 Krishnaswami KV, Somasundaram PR, Tripathy SP, Vaidynathan B, Radhakrishna S, Fox W. A randomised study of two policies for managing default in out-patient supplies of drugs for pulmonary tuberculosis in a large city in South India. Tubercle 1981; 61: 102-12.

17 Kaul SA. Trial for village health workers in a remote area of Himachal Pradesh. In: Alternative approaches to health care Delhi: Indian Council for Medical Research, 1976.

18 Mantel N. Evaluation of survival data and two new rank order statistics arising in its consideration. Cancer Order statistics arising

19 Coldman AJ, Elwood JM. Examining survival data. Can Med Assoc F 1979; 121: 1065-71.

20 Shanks NJ, Lambourne A, Kuhaymi RA, Humphries $M$ Sanford JRA. A new approach to tuberculosis notification. Epidemiol Community Health 1984; 38: 331-4. 